\title{
Measuring underlying energy efficiency in the GCC countries using a newly constructed dataset
}

\author{
Shahad Alarenan ${ }^{1} \cdot$ Anwar A. Gasim ${ }^{1} \cdot$ Lester C. Hunt ${ }^{2} \cdot$ Abdel Rahman Muhsen $^{1}$
}

Received: 4 February 2019 / Accepted: 22 July 2019 / Published online: 30 July 2019

(c) The Author(s) 2019

\begin{abstract}
Energy consumption accounts for most of global anthropogenic greenhouse gas emissions. Managing the growth in energy demand is therefore a key part of climate change mitigation. In the Gulf Cooperation Council (GCC) countries, energy consumption has been growing rapidly. Between 2004 and 2014, final energy consumption grew at an average annual rate of $6.8 \%$ compared to a global average of $1.8 \%$. Energy efficiency can help GCC countries manage their energy demand growth, but it is difficult to measure energy efficiency, so analysts often rely on indirect indicators such as energy intensity. Frontier analysis can be used to measure energy efficiency, but is data intensive. To undertake frontier analysis for the GCC countries it was therefore necessary to construct a new dataset, which was used for corrected ordinary least squares to estimate underlying energy efficiency between 2004 and 2014 for two key sectors in the GCC countries: residential electricity and road transport gasoline. The results suggest that underlying energy efficiency generally improved in the GCC region, in contrast to the trend of rising energy intensity that the region has been witnessing. The energy efficiency improvements may have been driven by global technical progress and tighter global fuel economy standards, of which the GCC countries were beneficiaries. With the provision of high quality, recent data with shorter lag times, frontier analysis could be used to provide prompt feedback on the impact of energy efficiency policies and programmes, leading to better outcomes.
\end{abstract}

Keywords Energy efficiency $\cdot$ Frontier analysis $\cdot$ Corrected ordinary least squares $\cdot$ Energy demand $\cdot$ Gulf Cooperation Council (GCC)

\section{Introduction}

Economic development, population growth, energy prices, and improvements in energy efficiency are key factors that affect the evolution of energy demand. The Gulf Cooperation Council (GCC), an economic union that includes Bahrain, Kuwait, Oman, Qatar, Saudi Arabia, and the United Arab Emirates (UAE), has experienced rapid economic and population growth over the last several decades. Between 2004 and 2014, real gross domestic product (GDP) in the GCC increased at an average annual rate of $5.3 \%$, while the population grew at $4.2 \%$ [1]. As would be expected, energy consumption in the region also grew rapidly. According to

Anwar A. Gasim

Anwar.Gasim@kapsarc.org

$1 \quad$ King Abdullah Petroleum Studies and Research Center (KAPSARC), Riyadh, Saudi Arabia

2 Economics and Finance, University of Portsmouth, Portsmouth, UK the IEA [2], final energy consumption in the GCC countries grew at an average annual rate of $6.8 \%$ over the period, which is noticeably higher than the global average of $1.8 \%$ (see Table 1 for a summary of the growth rates for key variables in the GCC countries). The relatively faster growth rate of energy consumption implies that energy intensity has been rising in the GCC countries, unlike most other countries in which energy intensity has been falling [2]. This has led to concerns that GCC countries are not efficient in their use of energy.

With their abundant fossil fuel supplies, GCC countries have been providing domestic consumers with energy at low administered prices. These energy prices have typically been set at levels far below international market prices, which arguably led to both relatively higher levels of energy consumption and lower levels of energy efficiency.

Several additional factors appear to contribute to their relatively higher levels of energy consumption. In the residential sector, electricity consumption is relatively higher because of the need for air conditioning in a region renowned 
Table 1 Average annual growth rates for real GDP, population, and energy consumption. Sources: World Bank and IEA

\begin{tabular}{lccccc}
\hline Country & Real GDP (\%) & Population (\%) & $\begin{array}{l}\text { Final energy } \\
\text { consumption } \\
(\%)\end{array}$ & $\begin{array}{l}\text { Residential electric- } \\
\text { ity consumption }(\%)\end{array}$ & $\begin{array}{l}\text { Gasoline } \\
\text { consumption } \\
(\%)\end{array}$ \\
\hline Bahrain & 5.0 & 5.4 & 5.3 & 5.9 & 5.1 \\
Kuwait & 3.1 & 5.6 & 4.9 & 4.9 & 3.7 \\
Oman & 4.4 & 5.6 & 17.7 & 9.2 & 11.6 \\
Qatar & 12.6 & 11.5 & 8.8 & 20.4 & 10.3 \\
Saudi Arabia & 5.5 & 2.5 & 6.0 & 6.4 & 6.4 \\
UAE & 3.8 & 8.6 & 7.1 & 7.3 & 8.8 \\
\hline
\end{tabular}

for its hot climate. In the road transport sector, urban sprawl and limited alternative transport options appear to have contributed to the GCC countries sharing some of the highest levels of gasoline consumption per capita globally.

Many energy efficiency policies focus on buildings (many of which are residential) and transport [3]. The GCC countries, however, implemented very few energy efficiency policies in both sectors during the 1990s and 2000s [4], although they have shown greater interest in energy efficiency in recent years given the rapid growth in energy consumption, a deeper awareness of the value and extent of wasted resources, and the pressures placed on government budgets in the face of low international oil prices.

Saudi Arabia, for example has recently invested in energy efficiency labelling and has been raising its minimum energy efficiency standards for appliances. For example, the minimum energy efficiency ratio for air conditioners was raised to 8.5 in late 2013 and subsequently to 9.8 for certain types of air conditioners, with further increases expected over the coming years $[5,6]$. Similar energy efficiency standards and regulations have been implemented in the GCC region or are currently being considered.

Measuring energy efficiency and tracking it can help analysts quantify the impact of policies such as energy efficiency labelling and minimum standards for appliances. But energy efficiency is difficult to measure. Therefore, analysts tend to use simpler, indirect indicators to measure and track energy efficiency. For the residential sector, energy use per capita is often used. A fall in electricity consumption per capita, for example, is often believed to be associated with energy efficiency improvements in residential buildings. Davis [7], for example explored the fall in residential electricity consumption per capita in the US and suggested that the recent uptake of energy efficient lighting is likely responsible for the fall. Another common indirect indicator is energy intensity. However, as Filippini and Hunt [8, 9] argue, such indirect indicators of energy efficiency can increase or decrease because of many different factors that are unrelated to energy efficiency. Filippini and Hunt [8] therefore advocate for the need to control for such factors when estimating energy efficiency by using frontier analysis.
Frontier analysis relaxes the assumptions of pure cost minimization, production maximization, or profit maximization, allowing for the introduction of inefficiency into the behaviour of economic agents. As discussed by Coelli et al. [10] and Kumbhakar et al. [11], there appear to be four theoretical models or functions for conducting frontier analysis:

- A production frontier model or function depicts the maximum possible output achievable for a given set of inputs. If producers are optimizing successfully, then they lie on the production frontier. In frontier analysis, this assumption about successful optimization is relaxed so that producers may be operating below the production frontier. If a producer is below the production frontier, then they are technically inefficient and must increase their technical efficiency to reach the frontier.

- A cost frontier model depicts the minimum possible cost given input prices and a certain level of output. If an economic agent is cost-minimizing, then they lie on the cost frontier. If their costs are higher than the minimum possible cost, then they lie above the frontier because of inefficiency. Unlike production frontier models, there are two sources of inefficiency in cost frontier models. First, an economic agent may have higher actual costs than the minimum possible because of technical inefficiency. Second, even if the production process is as technically efficient as possible, the agent may be able to reduce costs by choosing a 'better' combination of inputs. This is known as improving allocative inefficiency.

- Another important model that is used in frontier analysis is the profit frontier model. With production frontier models, inputs are assumed exogenous. With cost frontier models, output is assumed exogenous. With profit frontier models, both inputs and outputs are endogenous [11], which arguably results in a more realistic model for most producers.

- Distance frontier models are closely related to production frontier models and are particularly useful for dealing with multiple inputs and outputs. Distance frontier models allow users to describe production activities without specifying an objective such as profit maximization or 
cost minimization [10]. There are also two types of such models: input and output distance models.

Studies that attempt to measure efficiency through frontier analysis, whether using production, profit, distance, or cost frontier models, will employ either parametric or non-parametric methods (see [12] for a comparison and a bibliometric analysis of both methods). An advantage of the non-parametric method is that it does not require a specific functional form [10]. Data envelopment analysis (DEA) appears to be the most widely used non-parametric method in the literature. Parametric methods on the other hand require a specific functional form, and can be either deterministic or stochastic [9-11, 13]. The most widely used parametric methods appear to be corrected ordinary least squares (COLS) and stochastic frontier analysis (SFA).

In the field of energy economics, Filippini and Hunt [9] demonstrated that there are three functional specifications that are becoming commonly used for measuring energy efficiency: an energy requirement function (ERF), a Shephard energy distance function (SEDF), and the energy demand function (EDF). These functional specifications are derived from the theoretical models discussed previously. The ERF and SEDF are based on production and distance frontier models, respectively, and therefore only capture technical inefficiency. On the other hand, the EDF is analogous to a cost frontier model. As Filippini and Hunt [9] explained, the EDF depicts the minimum amount of energy needed to produce a certain level of output given energy prices and other factors. In the case of households, that output may be an energy service such as cooling or mobility. Since the EDF is analogous to a cost frontier model, it captures both technical and allocative inefficiency [9].

The number of studies attempting to measure energy efficiency across countries (or states) using such functional specifications has grown over the last few years, although they predominantly focus on developed countries. An early example is Boyd [14], who used an ERF to estimate the efficiency of energy use for the US manufacturing sector using disaggregated data. Another example is Filippini and Hunt [8], who used an EDF with annual data from 1978 to 2006 to estimate what they called underlying energy efficiency for a panel of 29 Organisation for Economic Co-operation and Development (OECD) countries. Moreover, they showed that energy intensity is generally a poor proxy for 'true' energy efficiency according to their measure of underlying energy efficiency.

Other studies that employed an EDF include Filippini and Hunt [15], Filippini et al. [16], Alberini and Filippini [17], Filippini and Hunt [18], Lundgren [19], and Otsuka [20] for the US residential sector, the European Union (EU) residential sector, the US residential sector using householdlevel data, the whole economy of 49 US states, Swedish multi-sectors, and the Japanese residential electricity sector, respectively; whereas, Zhou et al. [21], Adetutu et al. [22], Otsuka and Goto [23], and Marin and Palma [24] are examples of studies that employed the SEDF for the whole economies of the OECD countries, whole economies of OECD and non-OECD countries, regional jurisdictions of Japan, and EU countries, respectively. Kipouros [25] also employed an EDF (and compared the results with an input distance function approach) to measure underlying energy efficiency for a panel of 39 developing countries.

There are also a few examples of studies that have attempted to measure energy efficiency for China. Lin and Wang [26] employed an ERF for multi-industries in China. Lin and Du [27], Lin and Long [28], and Shen and Lin [29] employed a SEDF for China's different regions, chemical industry, and sub-industries, respectively; whereas, Broadstock et al. [30] and Filippini and Zhang [31] used an EDF for China's households and sub-industries, respectively.

Therefore, there appears to have been very little previous work on developing countries (other than China), with Adetutu et al. [22] and Kipouros [25] being the only exceptions. However, Adetutu et al. [22] used a SEDF benchmarking across both OECD and non-OECD countries and include only Kuwait, Saudi Arabia, and the UAE from the GCC, while Kipouros [25], who used an EDF, only included Saudi Arabia and Oman from the GCC. Furthermore, both studies focused on energy consumption at the whole economy level. Therefore, as far as we are aware, this is the first study to focus on measuring energy efficiency for all six GCC countries and for two key end-use sectors: residential electricity and road transport gasoline.

The choice of which functional specification to use (ERF, SEDF, or EDF) is often driven by data availability and the research questions being considered so, as shown above, various specifications have been applied in the literature to measure energy efficiency. This paper adopts the EDF because of its ability to capture both technical and allocative inefficiency.

It is also important to decide which frontier analysis method to use. Ideally, researchers should try different methods and compare the results, but the data do not always allow for this. As noted previously, COLS and SFA are arguably the most commonly employed parametric methods for frontier analysis. With COLS, the frontier is deterministic such that any deviations from the frontier are attributed to inefficiency. With SFA, as its name suggests, the frontier is stochastic, which allows a distinction between inefficiency and statistical noise. SFA thus relies on a two-part error term, where one part captures the effects of statistical noise, measurement error, and random shocks while the other part captures inefficiency [32]. Although SFA's two-part error term likely results in more realistic estimates of inefficiency, this paper uses COLS, which is amenable to smaller datasets, 
since the dataset for the GCC countries in this study is relatively small. ${ }^{1}$ Nevertheless, as stated by Giraleas et al. [35] in a study that compared COLS, SFA, and DEA, "deterministic approaches [such as COLS] perform adequately even under conditions of (modest) measure error" (p. 673).

The remainder of this paper is organized as follows. "Methods" presents the estimation strategy for the econometric models and the frontier approach used to estimate inefficiency. "Dataset construction" provides a comprehensive description of the newly constructed dataset to facilitate this study. "Results" presents the energy efficiency results. Finally, "Discussion" discusses the implications of the results and concludes.

\section{Methods}

To measure energy efficiency, EDFs are first estimated econometrically for the residential electricity and road transport gasoline sectors using OLS. The residuals from the estimated models are then used in COLS to estimate a relative measure of energy efficiency, which we call relative underlying energy efficiency.

Ideally, we would like to capture all heterogeneity that is not related to energy efficiency in the EDFs, so that the error terms or residuals can accurately reflect energy efficiency when used in COLS. We have therefore attempted to include as many relevant variables as possible. Of course, there will always be some heterogeneity left in the residuals that has not been controlled for, which will affect the estimates of relative underlying energy efficiency. Nevertheless, by focusing on the six GCC countries, which share many cultural, demographic, climatic, and behavioural characteristics, instead of expanding to the wider Middle East region, we should ensure that any 'uncaptured' heterogeneity is kept to a minimum.

\section{Measuring energy efficiency using corrected ordinary least squares}

The first step in COLS is to obtain estimates of the coefficients through OLS. The estimated function is then shifted downwards so that it reflects the minimum possible energy demand given a set of inputs.

The OLS residual is defined as follows:

$\widehat{u_{\mathrm{it}}}=e_{\mathrm{it}}-\widehat{e_{\mathrm{it}}}$,

\footnotetext{
${ }^{1}$ See Richmond [33] for an early discussion of COLS in a production context and Pollitt [34] for a discussion of how COLS was used by the UK electricity regulator for benchmarking the efficiency of UK electricity networks.
}

where $\widehat{u_{\mathrm{it}}}$ is the OLS residual, $e_{\mathrm{it}}$ is the natural logarithm of actual energy demand, and $\widehat{e_{i t}}$ is the predicted natural logarithm of energy demand, all for country $i$ in year $t$.

To use COLS, the OLS intercept is adjusted downwards by the minimum OLS residual [11]. This shifts the estimated EDF downwards so that it bounds all observations from below:

$\widehat{u_{\mathrm{it}}}-\min \left\{\widehat{u_{\mathrm{it}}}\right\}=e_{\mathrm{it}}-\left(\widehat{e_{\mathrm{it}}}+\min \left\{\hat{u_{\mathrm{it}}}\right\}\right)$.

The term in parentheses on the right-hand side of Eq. (2) represents the estimated frontier function [11]. Thus, the expression $e_{\mathrm{it}}-\left(\widehat{e_{\mathrm{it}}}+\min \left\{\widehat{u_{\mathrm{it}}}\right\}\right)$ reflects deviations above the frontier. As noted previously, this frontier describes the minimum possible energy demand given a set of inputs. The deviations from the frontier provide us with a measure of inefficiency, which we denote by $\widehat{z_{i t}}$. This measure of inefficiency captures both technical and allocative inefficiency.

$\widehat{z_{\mathrm{it}}}=\widehat{u_{\mathrm{it}}}-\min \left\{\widehat{u_{\mathrm{it}}}\right\}$.

The underlying energy efficiency of each observation, denoted by $\widehat{\mathrm{UEE}}_{\mathrm{it}}$, can then be calculated as follows:

$\widehat{\mathrm{UEE}_{\mathrm{it}}}=\exp \left(-\widehat{z_{\mathrm{it}}}\right)$.

The values of relative underlying energy efficiency therefore range from zero to one, with one representing the highest level of relative underlying energy efficiency.

\section{Estimating the EDFs}

Residential electricity demand $\left(e_{\mathrm{it}}^{\mathrm{R}}\right)$ was estimated using the following static specification:

$e_{i t}^{\mathrm{R}}=\widehat{\alpha_{0}^{\mathrm{R}}}+\widehat{\alpha_{1}^{\mathrm{R}}} p_{i t}^{\mathrm{R}}+\widehat{\alpha_{2}^{\mathrm{R}}} y_{i t}^{\mathrm{R}}+\widehat{\alpha_{3}^{\mathrm{R}}} \operatorname{pop}_{i t}^{\mathrm{R}}+\widehat{\alpha_{4}^{\mathrm{R}}} \operatorname{cdd}_{i t}^{\mathrm{R}}+\widehat{\alpha_{5}^{\mathrm{R}}} \mathrm{hs}_{\mathrm{i}}^{\mathrm{R}}+\widehat{u_{\mathrm{i}}^{\mathrm{R}}}$,

where the superscript $R$ denotes the residential electricity sector. The variables $p_{\mathrm{it}}^{R}$ and $y_{\mathrm{it}}^{\mathrm{R}}$ denote the average real residential electricity price and income in country $i$ in year $t$, respectively. The latter is measured using real GDP. The variable pop ${ }_{i t}^{\mathrm{R}}$ denotes the total population for country $i$ in year $t, \operatorname{cdd}_{\text {it }}^{\mathrm{R}}$ denotes the total cooling degree days for country $i$ in year $t$, and $\mathrm{hs}_{\mathrm{i}}^{\mathrm{R}}$ denotes household size for country $i$, which was estimated in either 2010 or 2011 (depending on the GCC country) and held fixed for all other years in the study period. All lower-case variables are in natural logarithms.

Transport gasoline demand $\left(e_{\mathrm{it}}^{\mathrm{T}}\right)$ was estimated using the following static specification:

$e_{\mathrm{it}}^{\mathrm{T}}=\widehat{\alpha_{0}^{\mathrm{T}}}+\widehat{\alpha_{1}^{\mathrm{T}}} p_{\mathrm{it}}^{\mathrm{T}}+\widehat{\alpha_{2}^{\mathrm{T}}} y_{\mathrm{it}}^{\mathrm{T}}+\widehat{\alpha_{3}^{\mathrm{T}}} \mathrm{pop}_{\mathrm{it}}^{\mathrm{T}}+\widehat{\alpha_{4}^{\mathrm{T}}} \mathrm{pc}_{\mathrm{it}}^{\mathrm{T}}+\widehat{\alpha_{5}^{\mathrm{T}}} \mathrm{rn}_{\mathrm{it}}^{\mathrm{T}}+\widehat{u_{\mathrm{it}}^{\mathrm{T}}}$

where the superscript $T$ denotes the road transport gasoline sector. The variable $p_{\mathrm{it}}^{\mathrm{T}}$ denotes the average real gasoline price in country $i$ in year $t$. The income $\left(y_{\mathrm{it}}^{\mathrm{T}}\right)$ and population 
$\left(\right.$ pop $\left._{i t}^{\mathrm{T}}\right)$ variables are the same as those used in the residential sector $\left(y_{i t}^{\mathrm{R}}\right.$ and pop $\left._{\mathrm{it}}^{\mathrm{R}}\right)$ described above. It is worth noting that gasoline demand in the GCC is largely used by private lightduty vehicles, while diesel is used by heavy-duty vehicles in the transport sector, which are largely owned by firms. The variables $\mathrm{pc}_{\mathrm{it}}^{\mathrm{T}}$ and $\mathrm{rn}_{\mathrm{it}}^{\mathrm{T}}$ denote the number of passenger cars and road network for country $i$ in year $t$, respectively. As noted previously, all lower-case variables are in natural logarithms.

The residuals from both regressions were then used to estimate relative underlying energy efficiency through COLS.

\section{Dataset construction}

\section{Income, population, and energy consumption}

Real GDP and population were obtained from the World Bank [1]. Residential electricity and gasoline consumption were from the IEA [2].

\section{Energy prices}

It proved impossible to find readily available data on energy prices in the GCC due to the absence of a single consistent source of data and the region's complex energy pricing frameworks. Although organizations such as the IEA publish consistent energy prices for most OECD economies, no organization yet publishes similar data for the GCC (and for many developing countries in general). ${ }^{2}$ We therefore constructed a new energy price dataset for each sector by combining numerous data sources.

\section{Electricity prices}

Electricity in the GCC is sold to consumers at low administered prices. These administered prices usually remain fixed until a government decree is issued to change them. We constructed a residential electricity price time series using reports by the Arab Union of Electricity [36-38] combined with numerous news articles and reports by various energy companies [39-44].

The presence of tiered prices and price differentiation made the process of estimating a single, average electricity price for each GCC country in each year difficult. Excluding Kuwait, countries in the GCC had tiered electricity prices throughout the study period (2004-2014). These tiered prices increased with higher levels of electricity

\footnotetext{
2 The IEA has recently started collecting and providing energy price data for the GCC countries, although the data remain relatively limited, particularly for time series or panel regression analysis.
}

consumption. Some GCC countries had three tiers, while others employed four. Furthermore, tier sizes differed between countries, although the first two tiers generally covered between zero and $4000 \mathrm{kw}$-h of electricity consumption per month. The average monthly electricity consumption of most households in the GCC is believed to lie within this range. Further complicating matters was the price differentiation in Qatar and the UAE, where electricity was supplied to citizens at relatively lower prices. In fact, electricity was provided free to Qatari citizens during the study period. Furthermore, in the UAE electricity was supplied at different prices across the different emirates.

We dealt with the issue of tiered prices by taking an average of the first two tiers to obtain a single price. In the case of Kuwait, estimating an average price was straightforward since there were no tiers. In the cases of Bahrain, Oman, and Saudi Arabia, the average price of electricity was defined to be an average of the prices at the first two tiers. In Qatar, the average price of electricity for citizens was zero, while expatriates faced multiple tiers. Therefore, we estimated a weighted average of the average prices for citizens and expatriates, where the weights depended on population shares. In the case of the UAE, an average price for Dubai and Abu Dhabi was estimated using the same approach for Qatar because both emirates had different prices for citizens and expatriates. These two averages were then averaged again using population shares to obtain a single electricity price for the whole of the UAE. (This approach overlooks the electricity prices in the other five emirates, however, due to a lack of data.)

\section{Gasoline prices}

Several grades of gasoline are sold at considerably different prices in the GCC region. For example, in 2014 Saudi Arabia sold 95-octane gasoline at 0.60 Saudi Riyals per litre, which was $33 \%$ more expensive than 91-octane gasoline. Similar price differences exist in the other GCC countries as well. The World Bank [1], however, only provides prices of super gasoline, which is usually the 95 octane gasoline in a country. Further complicating matters, the World Bank [1] reports gasoline prices in even years only (i.e. 2000, 2002, 2004, etc.). In many cases, the gasoline prices reported in consecutive even years for a country in the GCC were equal, implying the same gasoline price during the odd year in between. In other cases, different gasoline prices were reported in consecutive even years due to a government decree that changed gasoline prices. In such cases, the gasoline prices in odd years were found through news articles that announced the changes $[45,46]$. In a few cases, however, no data were found to fill the unreported odd years, resulting in an unbalanced panel, where the years of missing gasoline price data were eliminated from the model. The missing data points were for Qatar in 2005 and 2013 and the UAE in 2005 and 2009. 


\section{Additional sector-specific variables}

There are several sector-specific variables that can influence energy demand. By including as many of these variables as possible, the residuals from the econometrically estimated EDFs can provide better estimates of relative underlying energy efficiency when used in COLS.

For the residential sector, we included household size, obtained from Nakono [47] and NCSI [48]. We also included cooling degree days for each GCC country, which we calculated using average monthly temperature data obtained from the Climate Change Knowledge Portal [49]. To calculate the average monthly cooling degree days, we set $18{ }^{\circ} \mathrm{C}$ as the baseline temperature and calculated the difference between the average monthly temperature and the baseline:

$\mathrm{AMCDD}_{\mathrm{imt}}=\mathrm{ND}_{\mathrm{m}} \times\left(\mathrm{AMT}_{\mathrm{imt}}-18\right)$, for $\mathrm{AMT}_{\mathrm{imt}} \geq 18$,

where $\mathrm{AMCDD}_{\text {imt }}$ denotes the average monthly cooling degree days and $\mathrm{AMT}_{\mathrm{imt}}$ the average monthly temperature, all for country $i$ in month $m$ and year $t$ ND $_{\mathrm{m}}$ denotes the number of days in each month $m$.

The average monthly cooling degree days were calculated for each GCC country in each month between 2004 and 2014. They were then converted into annual cooling degree days, denoted by $\mathrm{CDD}_{\mathrm{it}}$, by taking the sum across all 12 months for each year:

$C D D_{i t}=\sum_{m=1}^{m=12} A M C D D_{i m t}$

For the transport sector, we included the number of passenger cars, obtained from OICA [50], the WRS [51], and SESRIC [52]. We also included the total road network. However, the readily available road network data on GCC countries across a number of sources is of limited use in our models $[1,51,53]$. The reported data, which were more or less the same across the three sources, appear to have been estimated by a different method by each country. According to the reported data, the UAE for example, which has a land area of $83,600 \mathrm{~km}^{2}$, had a reported road network that is less than half of Qatar's, a considerably smaller nation with a land area of $11,610 \mathrm{~km}^{2}$. This is highly unlikely. These figures likely stem from the UAE reporting the length of its motorway road network only, while Qatar may be reporting the total length of its road network, including motorways, streets, and service roads. In other words, the road network data appear to be 'comparing apples to oranges'. The use of such data in our econometric models would likely yield misleading coefficients and is thus of limited use.

To overcome this issue, the total road network in each GCC country was estimated using geographic information system (GIS) analysis. Our approach rested on linking the size of urbanized areas in each country to its road network. Two primary datasets were used in the road network estimation process, namely:

- Open street map (OSM) A crowdsourced spatial database providing free global road data with a completeness rate reaching 89\% [54]. A data dump for the roads in GCC countries was acquired from the OSM database [55]. These data effectively form a snapshot that includes all the roads in each GCC country as of October 2017.

- Global human settlement (GHS) A dataset that includes two GIS layers representing built-up (i.e. urban) areas as derived from Landsat image collections [56]. The dataset covers the years 2000 and 2014.

Given the datasets identified above, ArcGIS was used to estimate the total road network in each GCC country for the years 2000 and 2014. The missing data in between were then generated using linear extrapolation. The growth in the road network over this period was approximated by the growth in the urban areas as identified by GIS. We effectively assumed that the growth in the total road network was driven by the expansion of cities through new urban areas, while the roads that connected cities were fixed. Given the assumptions, it is likely that the total road network estimates for the year 2000 were overestimated using our approach. However, the overestimates would be consistent across the six countries. Thus, the approach that was used, although not perfect, provides a consistent 'apples-to-apples' comparison of the total road network in GCC countries. The data are shown in Table 2. More details on the construction of the road network dataset can be found in Appendix A.

\section{Results}

\section{Residential electricity sector}

\section{Estimated residential energy demand model}

The estimated residential electricity demand models are shown in Table 3. The estimated OLS coefficients for both Specification 1 and Specification 2 for the price, income, population, climate, and household size variables are all statistically significant at least at the $1 \%$ level. ${ }^{3},{ }^{4}$ All the

\footnotetext{
${ }^{3}$ Given this is a benchmarking exercise and that the time series spans a relatively short period, testing for unit roots is not undertaken in this type of analysis.

${ }^{4}$ Dummy variables were included when there were sharp unexplained changes in the dependent variable, most likely the result of issues in the underlying data. This appeared to be the case for residential electricity consumption in Qatar in 2008.
} 
Table 2 Total road network in each GCC country between 2000 and 2014 (units: km).

Sources: OSM, GHS, and

KAPSARC analysis

\begin{tabular}{lllllll}
\hline Year & Bahrain & Qatar & Kuwait & Oman & UAE & Saudi Arabia \\
\hline 2000 & 5287.07 & $12,138.69$ & $16,887.58$ & $36,738.25$ & $50,634.91$ & $178,736.60$ \\
2001 & 5300.33 & $12,205.90$ & $16,967.61$ & $36,889.72$ & $50,941.02$ & $180,286.59$ \\
2002 & 5313.59 & $12,273.10$ & $17,047.64$ & $37,041.18$ & $51,247.13$ & $181,836.58$ \\
2003 & 5326.85 & $12,340.31$ & $17,127.68$ & $37,192.65$ & $51,553.23$ & $183,386.56$ \\
2004 & 5340.11 & $12,407.52$ & $17,207.71$ & $37,344.11$ & $51,859.34$ & $184,936.55$ \\
2005 & 5353.37 & $12,474.73$ & $17,287.74$ & $37,495.58$ & $52,165.45$ & $186,486.54$ \\
2006 & 5366.63 & $12,541.94$ & $17,367.77$ & $37,647.04$ & $52,471.55$ & $188,036.53$ \\
2007 & 5379.89 & $12,609.15$ & $17,447.80$ & $37,798.51$ & $52,777.66$ & $189,586.51$ \\
2008 & 5393.15 & $12,676.36$ & $17,527.83$ & $37,949.97$ & $53,083.77$ & $191,136.50$ \\
2009 & 5406.41 & $12,743.57$ & $17,607.87$ & $38,101.44$ & $53,389.87$ & $192,686.49$ \\
2010 & 5419.67 & $12,810.78$ & $17,687.90$ & $38,252.90$ & $53,695.98$ & $194,236.48$ \\
2011 & 5432.93 & $12,877.99$ & $17,767.93$ & $38,404.37$ & $54,002.09$ & $195,786.47$ \\
2012 & 5446.19 & $12,945.20$ & $17,847.96$ & $38,555.83$ & $54,308.19$ & $197,336.45$ \\
2013 & 5459.45 & $13,012.41$ & $17,927.99$ & $38,707.30$ & $54,614.30$ & $198,886.44$ \\
2014 & 5472.71 & $13,079.62$ & $18,008.02$ & $38,858.76$ & $54,920.40$ & $200,436.43$ \\
\hline
\end{tabular}

Table 3 Estimated residential electricity demand models

\begin{tabular}{|c|c|c|c|c|}
\hline \multicolumn{5}{|c|}{ Dependent variable: residential electricity consumption } \\
\hline \multirow[t]{2}{*}{ Independent variables } & \multicolumn{2}{|c|}{ Specification 1} & \multicolumn{2}{|c|}{$\begin{array}{l}\text { Specification } 2 \\
\text { (preferred) }\end{array}$} \\
\hline & Coeff. & Std. err. & Coeff. & Std. err. \\
\hline Real price of electricity & $-0.457 * * *$ & $(0.032)$ & $-0.544 * * *$ & $(0.024)$ \\
\hline Income & $0.161 * * *$ & $(0.047)$ & $0.315 * * *$ & $(0.037)$ \\
\hline Population & $0.917 * * *$ & $(0.054)$ & $0.754 * * *$ & $(0.042)$ \\
\hline Cooling degree days & $1.206^{* * *}$ & $(0.267)$ & $0.879 * * *$ & $(0.186)$ \\
\hline Household size & - & - & $1.931 * * *$ & $(0.231)$ \\
\hline Constant & $15.737 * * *$ & $(1.312)$ & $19.366 * * *$ & $(0.994)$ \\
\hline Dummy Qatar08 & $-0.546 * * *$ & $(0.157)$ & $-0.373 * * *$ & $(0.109)$ \\
\hline R-squared & 0.98170 & & 0.99160 & \\
\hline Adjusted R-squared & 0.98020 & & 0.99080 & \\
\hline $\begin{array}{l}\text { Standard error of } \\
\text { regression }\end{array}$ & 0.15343 & & 0.10467 & \\
\hline $\begin{array}{l}\text { Akaike information } \\
\text { criterion }\end{array}$ & -54.42780 & & -104.0134 & \\
\hline
\end{tabular}

The *,**, and $* * *$ denote statistical significance at the $10 \%, 5 \%$, and $1 \%$ level

coefficients have the expected signs, except for the household size variable. For this reason, two models are presented: one with and one without the household size variable. Additional robustness regressions that incorporated time trends and time dummy variables, shown in Appendix B, confirm the robustness of these models.

For many countries, one would expect smaller household sizes to lead to higher energy consumption. For example, when a married couple sharing a single house separate and move into two houses, average household size decreases while energy consumption usually increases. Therefore, coefficients for household size are generally expected to be negative. However, the estimated positive coefficient may be capturing differences between the ratio of expatriate and citizen households in GCC countries. Regional surveys often reveal considerable differences between citizen and expatriate households. NCSI [48], for example showed that the average household size in Oman for citizens only was 8.1 individuals per household in 2010. When expatriates were included in the calculation, average household size fell to 6.1. Therefore, assuming that citizens in GCC countries share similarly large household sizes, and that expatriates, many of whom fall in the lower-income category, live in smaller houses that consume less electricity, then a larger household size may point to a smaller share of expatriate households, which appear to consume less electricity.

Given that all variables are entered in logarithmic form, the estimated coefficients are long-run elasticities. The estimation results reveal that residential electricity demand in the GCC region is somewhat price inelastic, with estimated elasticities between -0.46 and -0.54 . They also reveal that demand is income inelastic, with estimated elasticities ranging from 0.16 to 0.32 . The population elasticity is relatively more elastic, with estimated values between 0.75 and 0.92 . Finally, the cooling degree days elasticity was found to range from 0.88 (somewhat inelastic) to 1.20 (elastic).

As shown by Atalla and Hunt [57], earlier econometric studies of residential electricity demand in the GCC generated small income and price elasticities, while more recent studies revealed relatively larger elasticities. Using structural time series models, Atalla and Hunt [56] found that the longrun income elasticity ranged from 0.43 to 0.71 across the six GCC countries, suggesting that electricity demand in the GCC was income inelastic. These estimates are relatively more elastic than the coefficients estimated in this paper. 
Fig. 1 Relative underlying energy efficiency of residential electricity consumption for the six GCC countries

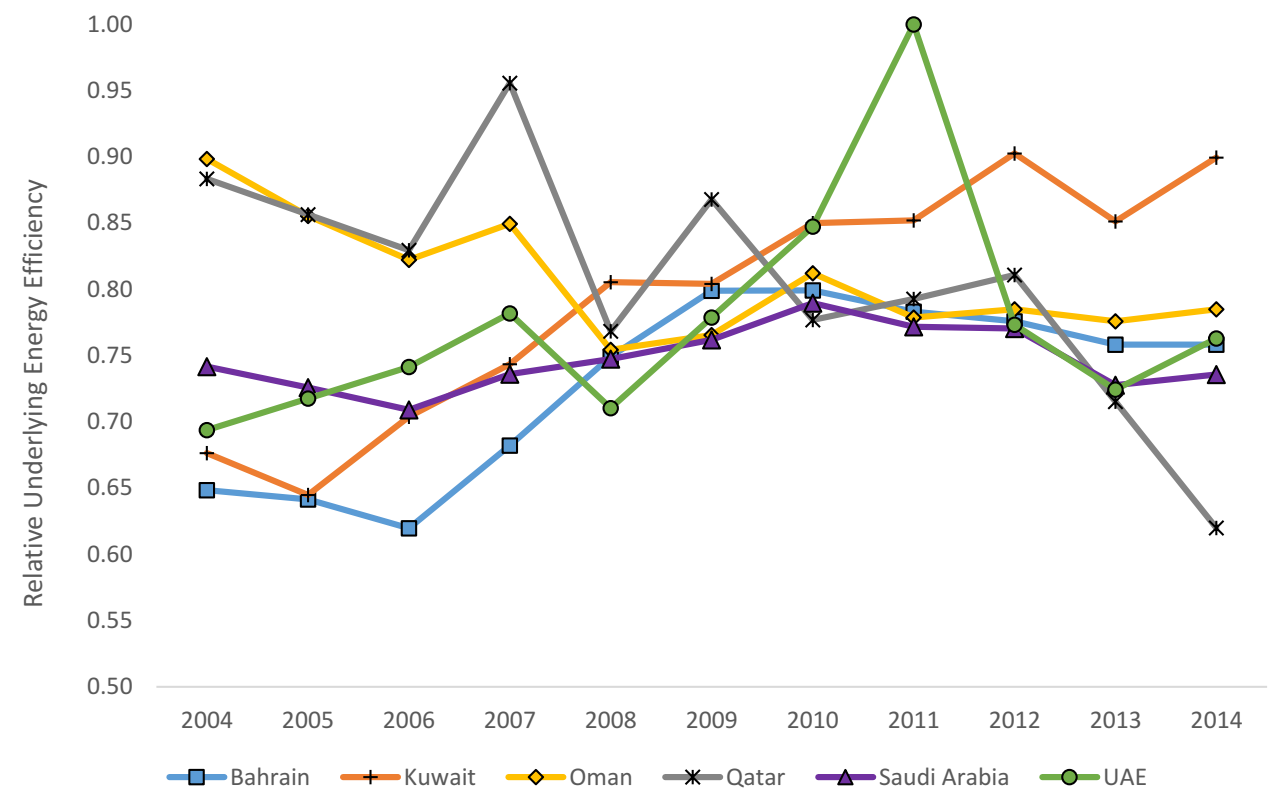

Furthermore, they found that the price elasticity ranged from -0.10 to -0.16 , revealing demand to be strongly price inelastic. Although this paper also finds residential electricity demand to be price inelastic, the estimated coefficients by Atalla and Hunt [57] are relatively more inelastic. They also found that demand is population inelastic (except for Qatar), with estimates ranging from 0.68 to 1.00 . These estimates are in line with the findings from our panel model.

\section{Residential electricity sector efficiencies}

Using the outlined COLS procedure, relative underlying energy efficiency was estimated for each GCC country in each year based on the preferred specification in Table 3 (although the results did not vary considerably between specifications). The estimated energy efficiencies are shown in Fig. 1.

The analysis reveals the UAE in 2011 to be the most energy efficient in residential electricity consumption. It also reveals Bahrain in 2006 to be the least energy efficient. The trends also show that Kuwait, Bahrain, and the UAE witnessed improvements of 33.0, 17.0, and 10.0 percentage points in their underlying energy efficiencies between 2004 and 2014. In contrast, Qatar and Oman witnessed deteriorations of 29.8 and 12.7 percentage points over the same period. In Saudi Arabia, underlying energy efficiency remained largely flat, with a change of only -0.8 percentage points over the 11-year period.

It appears that none of the countries that experienced improving energy efficiency implemented significant energy efficiency programmes during the study period. This suggests that some GCC countries may have been beneficiaries of global improvements in appliance technology. By 2014,
Kuwait appeared to be the most efficient in residential electricity consumption. While it may be difficult to attribute a single cause to this result, it is worth noting that Kuwait was the first GCC country to implement thermal insulation regulations (in 1983), which were later revised in 2010 [4]. Nevertheless, because of the lags between the implementation of a policy and its impact on energy efficiency, it can be difficult to attribute a change in the trend to a single energy efficiency policy.

\section{Road transport gasoline sector}

\section{Estimated gasoline demand model}

The preferred estimated gasoline demand model is shown in Table 4. The estimated OLS coefficients for the price, income, population, passenger cars, and road network variables are all statistically significant at least at the 5\% level and with the expected signs. Additional regressions incorporating time trends and time dummy variables are shown in Appendix B, providing evidence on the robustness of this model.

The estimation results reveal that gasoline demand in the GCC region is price inelastic, with an estimated elasticity of -0.14 . Compared to our estimated residential electricity demand models, gasoline demand appears to be considerably more price inelastic. The estimation results also reveal gasoline demand to be income inelastic, with an estimated elasticity of 0.19 . This is in line with the income elasticity estimated for the residential electricity demand model. The population elasticity was found to be relatively more elastic than the income elasticity, with a value of 0.57 . This is again similar to what was observed with the estimation results 
Table 4 Estimated gasoline demand models

\begin{tabular}{lll}
\hline Dependent variable: gasoline consumption & \\
\hline Independent variables & \multicolumn{2}{l}{ Preferred specification } \\
\cline { 2 - 3 } & \multicolumn{1}{l}{ Coeff. } & Std. err. \\
\hline Real price of gasoline & $-0.137^{* *}$ & $(0.059)$ \\
Income & $0.195^{* * *}$ & $(0.042)$ \\
Population & $0.572^{* * *}$ & $(0.058)$ \\
Passenger cars & $0.293^{* * *}$ & $(0.064)$ \\
Road network & $0.087^{* * *}$ & $(0.032)$ \\
Constant & $-10.851^{* * *}$ & $(0.580)$ \\
R-squared & 0.98500 & \\
Adjusted R-squared & 0.98370 & \\
Standard error of regression & 0.14519 & \\
Akaike information criterion & -57.64543 &
\end{tabular}

The *,**, and *** denote statistical significance at the $10 \%, 5 \%$, and $1 \%$ level

from the residential electricity demand model. Gasoline demand was also found to be inelastic with respect to the number of passenger cars, with an estimated elasticity of 0.29 , and the length of the road network, with an estimated elasticity of 0.09 .

Atalla et al. [58] showed that gasoline demand in Saudi Arabia was price and income inelastic, with long-run price and income elasticities of -0.09 to -0.15 and 0.15 to 0.61 , respectively. In their review of past econometric studies of gasoline demand, for both Saudi Arabia individually and the GCC countries, they found that in general the estimated elasticities were relatively small in almost all of the studies. These results are in line with the gasoline demand elasticities estimated in this paper.

\section{Transport sector efficiencies}

Using COLS, relative underlying energy efficiency was estimated for each GCC country in each year based on the model from Table 4 . The estimated energy efficiencies are shown in Fig. 2.

The results in Fig. 2 reveal Bahrain in 2011 to be the most energy efficient in gasoline consumption and Oman in 2012 to be the least efficient. The trends also show that Bahrain, Kuwait, Qatar, and Saudi Arabia witnessed improvements of 26.0, 20.5, 8.1, and 7.4 percentage points in their underlying energy efficiencies. In contrast, Oman and the UAE witnessed deteriorations of 32.0 and 25.1 percentage points.

In four of the GCC countries, energy efficiency in passenger cars appears to have improved. This may have been driven by tighter global fuel economy standards and/or a shift in preferences towards smaller cars, which tend to be relatively more fuel efficient. Although Oman and the UAE may have been beneficiaries of tighter global fuel economy standards as well, their underlying energy efficiencies appear to have deteriorated, possibly due to a growing preference for larger cars with lower fuel economies.

\section{Benchmarking countries using different indicators}

Following Filippini and Hunt $[8,15]$, we rank the GCC countries in terms of energy efficiency using both indirect indicators and our estimated measures of underlying energy efficiency. The comparisons are shown in Table 5. If the country that had the lowest energy use per capita was the most efficient and vice versa, then the rankings would be the same for both indicators of energy efficiency. However,
Fig. 2 Relative underlying energy efficiency of gasoline consumption for the six GCC countries

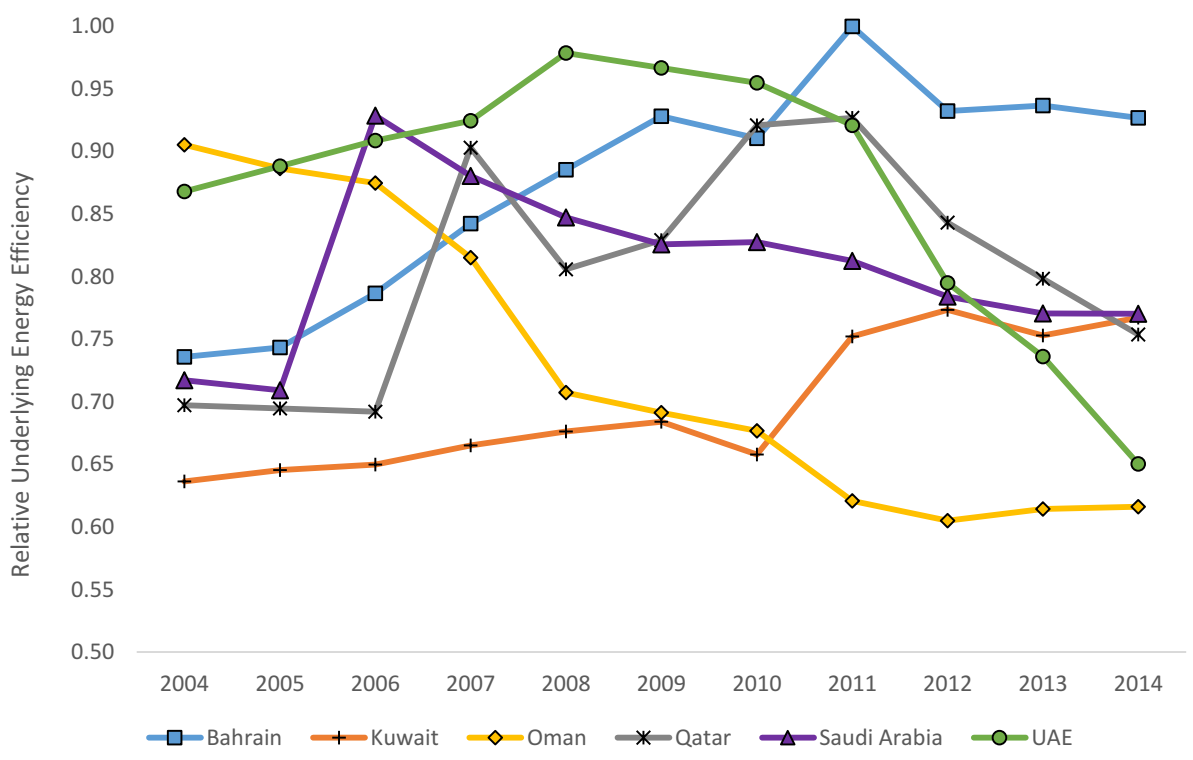


Table 5 The rankings of countries in 2014 according to both energy use per capita and relative underlying energy efficiency

\begin{tabular}{llllll}
\hline Rankings & \multicolumn{2}{l}{ Residential electricity } & & \multicolumn{2}{l}{ Road transport gasoline } \\
\cline { 2 - 3 } & $\begin{array}{l}\text { Underly- } \\
\text { ing energy } \\
\text { efficiency }\end{array}$ & Electricity use per capita & & $\begin{array}{l}\text { Underly- } \\
\text { ing energy } \\
\text { efficiency }\end{array}$ & Gasoline use per capita \\
\hline 1st (most efficient) & Kuwait & Oman & Bahrain & Bahrain \\
2nd & Oman & UAE & Saudi Arabia & Oman \\
3rd & UAE & Saudi Arabia & Kuwait & Saudi Arabia \\
4th & Bahrain & Bahrain & Qatar & Kuwait \\
5th & Saudi Arabia & Qatar & UAE & Qatar \\
6th (least efficient) & Qatar & Kuwait & Oman & UAE \\
Correlation coefficient & 0.136 & & -0.540 & \\
\hline
\end{tabular}

Table 5 reveals that the rankings differ depending on which indicator is used to measure energy efficiency. These differences hold true for both the rankings calculated using the latest available year of data (2014, as shown in the table) and the rankings calculated using averages for different periods. This suggests that indirect indicators such as energy use per capita and energy intensity are not very useful at ranking countries in terms of energy efficiency relative to one another, which is consistent with what Filippini and Hunt $[8,15]$ observed. The weak correlation coefficients between both indicators of energy efficiency also provide further evidence, particularly for the residential electricity sector. If energy use per capita and energy efficiency were perfectly correlated, the coefficient would have been -1 .

\section{Discussion}

Energy consumption in the GCC region has grown rapidly over the last several decades. With low administered energy prices, rapid population growth, and extensive economic development, final energy consumption across the GCC countries increased by an average of $6.8 \%$ per annum between 2004 and 2014-almost four times faster than the global average. Carbon dioxide emissions in the GCC countries, driven by energy consumption, grew at a similarly rapid pace.

Energy efficiency carries the potential to mitigate such growth in energy demand and carbon dioxide emissions, putting the GCC countries on a more sustainable pathway. There is huge potential for energy efficiency, and policymakers in GCC countries have recently been studying and implementing a wide range of energy efficiency programmes, such as minimum energy efficiency standards, thermal insulation regulations, and energy efficiency labelling.
To measure the impact of such programmes, it is important to be able to measure energy efficiency accurately for a country or one of its sectors, and to benchmark with other similar countries. This is where frontier analysis can play a key role.

This study constructed an energy-related dataset for the period 2004-2014, which was then used to measure energy efficiency in the residential electricity and road transport gasoline sectors in the GCC countries. The results revealed that Kuwait, Bahrain, and the UAE improved their energy efficiency in their residential electricity sectors between 2004 and 2014, while it remained largely flat in Saudi Arabia. In contrast, Qatar and Oman saw deteriorations in energy efficiency over the same period. In the gasoline sector, Bahrain, Kuwait, Qatar, and Saudi Arabia improved their energy efficiency, while Oman and the UAE saw deteriorations. Nevertheless, these results suggest that underlying energy efficiency in general improved in the GCC region in those two sectors, in contrast to the trend of rising energy intensity that the region has been witnessing.

Although there were few energy efficiency policies implemented in the GCC countries over the study period, energy efficiency improvements were observed in the estimated underlying energy efficiency trends. These improvements may have been driven by global improvements in appliance technology and tighter global fuel economy standards, of which the GCC countries were beneficiaries. Nevertheless, there may be huge potential for greater energy efficiency improvements in the GCC countries through the implementation of domestic energy efficiency programmes. Frontier analysis could be used to track the impact of such programmes on energy efficiency, both on its evolution and its relative level with respect to other countries.

Future work on measuring energy efficiency in the GCC through frontier analysis could be accelerated and improved through the provision of higher quality, more recent data with shorter lag times. As shown in this paper, 
energy-related data for many of the GCC countries were missing, and some of the available data were not comparable, as in the case of the road network. Greater investment in the provision of consistent, high-quality data combined with short lag times could allow analysts to quickly measure and track energy efficiency through frontier analysis, providing policymakers with prompt feedback on the impact of energy efficiency policies and programmes and helping them adjust those programmes effectively to achieve optimal outcomes.

\begin{abstract}
Acknowledgements An earlier version of this paper was presented and discussed at the 2018 41st IAEE International Conference in Groningen, Netherlands, and we are grateful to all the participants for their comments and suggestions. We would also like to thank Carlo Andrea Bollino, Massimo Filippini, Walid Matar, Jeyhun Mikayilov, and Axel Pierru for their helpful comments and suggestions. Nevertheless, we are responsible for all errors and omissions. The views expressed in this paper are those of the authors and do not necessarily represent the views of their affiliated institutions. This research did not receive any specific grant from funding agencies in the public, commercial, or not-for-profit sectors.
\end{abstract}

\section{Compliance with ethical standards}

Conflict of interest The authors declare that they have no conflict of interest.

Open Access This article is distributed under the terms of the Creative Commons Attribution 4.0 International License (http://creativeco mmons.org/licenses/by/4.0/), which permits unrestricted use, distribution, and reproduction in any medium, provided you give appropriate credit to the original author(s) and the source, provide a link to the Creative Commons license, and indicate if changes were made.

\section{Appendix A: Constructing the total road network data}

Estimation of the road network for each of the six GCC countries was completed via the following steps:

Initially, the OSM GIS layer was filtered to include only the roads that are relevant to this study, that is, those constructed to be used by motor vehicles. The roads were then classified into two categories: urban or interurban. Urban roads were defined to be located completely within urbanized areas, while interurban roads were defined to be the highways that extended beyond urban areas to connect cities and towns.

The total length of urban and interurban roads in each GCC country in 2017 was calculated using OSM GIS. Furthermore, the size of the urban areas in each GCC country for the years 2000 and 2014 was calculated using the GHS dataset.

The total road network in 2017 was assumed to be equal to the total road network in 2014. It is almost certain that the road network grew between 2014 and 2017, but given the fall in international oil prices that started in 2014, the relationship between public spending and oil revenues in GCC economies, and the vast road infrastructure that had already been developed over the past several decades, it is likely that the growth was limited. Thus, the total road network in 2014 for each GCC country was assumed to be equal to that of 2017 , as shown in the following equation:

$\mathrm{TR}_{i 2014}=\mathrm{TR}_{i 2017}=\mathrm{UR}_{i 2017}+\mathrm{IUR}_{i}=\mathrm{UR}_{i 2014}+\mathrm{IUR}_{i}$,

where $\mathrm{TR}_{\mathrm{it}}$ denotes the total road network for country $i$ in year $t, \mathrm{UR}_{\mathrm{it}}$ the urban road network for country $i$ in year $t$, and IUR $\mathrm{I}_{\mathrm{i}}$, the interurban road network for each country $i$, which is assumed to be fixed over the study period. In other words, any growth in the total road network during the period 2000-2014 is assumed to be driven entirely by the growth of urban areas, as cities expanded and grew larger while the roads that connect cities remained fixed. As noted previously, we assumed no growth in the urban road network between 2014 and 2017 because of data limitations, but this is not likely to be a major issue given the fall in international oil prices and limited government spending during these 3 years.

An urban road density factor was estimated for each GCC country by dividing the 2014 urban road network by the 2014 urban area, as follows:

$\mathrm{DF}_{\mathrm{i}}=\frac{\mathrm{UR}_{\mathrm{i} 2014}}{\mathrm{UA}_{\mathrm{i} 2014}}$

where $\mathrm{DF}_{\mathrm{i}}$ denotes the road density factor for country $i$ and $\mathrm{UA}_{\mathrm{it}}$ the urban area for country $i$ in year $t$. The density factor is assumed constant over time, allowing the urban road network in the year 2000 to be estimated as follows:

$\mathrm{UR}_{\mathrm{i} 2000}=\mathrm{DF}_{\mathrm{i}} \times \mathrm{UA}_{\mathrm{i} 2000}$.

With a fixed interurban road network, the total road network in 2000 can be calculated as follows:

$\mathrm{TR}_{\mathrm{i} 2000}=\mathrm{UR}_{\mathrm{i} 2000}+\mathrm{IUR}_{\mathrm{i}}$.

The total road network between the years 2000 and 2014 was then obtained using linear extrapolation.

\section{Appendix B: Robustness check regressions with time trends and time dummy variables}

Time trends and time dummy variables can be added to energy demand models to capture changes in technical progress and other unobserved factors. However, the inclusion of time dummies in a COLS regression would prevent 
Table 6 Estimated residential electricity demand models

\begin{tabular}{|c|c|c|c|c|c|c|}
\hline \multicolumn{7}{|c|}{ Dependent variable: residential electricity consumption } \\
\hline \multirow[t]{2}{*}{ Independent variables } & \multicolumn{2}{|c|}{ Preferred specification } & \multicolumn{2}{|c|}{ With a time trend } & \multicolumn{2}{|c|}{ With time dummies } \\
\hline & Coeff. & Std. err & Coeff. & Std. err. & Coeff. & Std. err. \\
\hline Income & $0.315^{* * *}$ & $(0.037)$ & $0.308 * * *$ & $(0.037)$ & $0.273 * * *$ & $(0.037)$ \\
\hline Real price of electricity & $-0.544 * * *$ & $(0.024)$ & $-0.553 * * *$ & $(0.025)$ & $-0.555^{* * *}$ & $(0.024)$ \\
\hline Population & $0.754 * * *$ & $(0.042)$ & $0.768 * * *$ & $(0.042)$ & $0.818 * * *$ & $(0.044)$ \\
\hline Cooling degree days & $0.879 * * *$ & $(0.186)$ & $0.946 * * *$ & $(0.190)$ & $1.237 * * *$ & $(0.207)$ \\
\hline Household size & $1.931 * * *$ & $(0.231)$ & $1.934 * * *$ & $(0.229)$ & $1.857 * * *$ & $(0.222)$ \\
\hline DummyQatar08 & $-0.373 * * *$ & $(0.109)$ & $-0.376 * * *$ & $(0.108)$ & $-0.398 * * *$ & $(0.114)$ \\
\hline Constant & $19.366^{* * *}$ & (0.994) & $19.723 * * *$ & $(1.014)$ & $-20.829 * * *$ & $(1.041)$ \\
\hline Time trend & - & - & -0.006 & $(0.004)$ & - & - \\
\hline DummyTime05 & - & - & - & - & 0.056 & $(0.057)$ \\
\hline DummyTime06 & - & - & - & - & 0.014 & $(0.058)$ \\
\hline DummyTime07 & - & - & - & - & -0.064 & $(0.058)$ \\
\hline DummyTime08 & - & - & - & - & -0.017 & $(0.061)$ \\
\hline DummyTime09 & - & - & - & - & -0.075 & $(0.059)$ \\
\hline DummyTime10 & - & - & - & - & $-0.127 * *$ & $(0.063)$ \\
\hline DummyTime11 & - & - & - & - & $-0.116^{*}$ & $(0.059)$ \\
\hline DummyTime12 & - & - & - & - & -0.096 & $(0.060)$ \\
\hline DummyTime13 & - & - & - & - & 0.010 & $(0.058)$ \\
\hline DummyTime14 & - & - & - & - & -0.035 & $(0.060)$ \\
\hline R-squared & 0.99160 & & 0.99190 & & 0.99570 & \\
\hline Adjusted R-squared & 0.99080 & & 0.99090 & & 0.99490 & \\
\hline Standard error of regression & 0.10467 & & 0.10365 & & 0.07807 & \\
\hline Akaike information criterion & -104.0134 & & -104.433 & & -103.29910 & \\
\hline
\end{tabular}

The table shows the estimated coefficients and their standard errors

The $*, * *$, and $* * *$ denote statistical significance at the $10 \%, 5 \%$, and $1 \%$ level

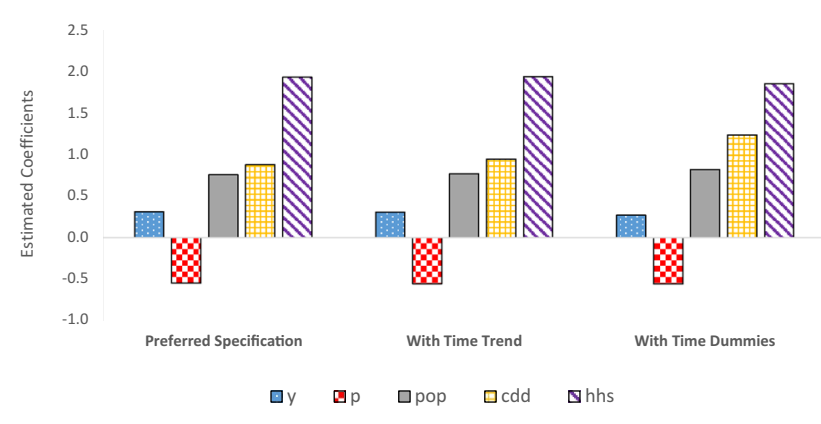

Fig. 3 Estimated coefficients for three specifications of the residential electricity demand model

us from observing the changes in estimated underlying energy efficiency over time relative to the benchmark. Nevertheless, as a robustness check, we ran regressions for both residential electricity and gasoline that included time trends and time dummy variables.
Table 6 shows that the specifications for residential electricity that included a time trend or time dummies yielded similar estimated coefficients for the variables included in the preferred models in the paper, all of which remained statistically significant. This robustness is also illustrated in Fig. 3. Furthermore, the time trend was not found to be statistically significant, while in the case of the time dummies, only two of them were found to be statistically significant (for the years 2010 and 2011). Since neither the time trend nor the time dummies were generally statistically significant, they were not included in the preferred specification.

Table 7 shows the impact of adding a time trend or time dummies to the preferred estimated transport gasoline specification. As with residential electricity, the time trend and time dummies were generally not statistically significant and did not alter the estimated coefficients for the variables included in the preferred models in any considerable way as illustrated in Fig. 4. Therefore, also similar to 
Table 7 Estimated gasoline demand models

\begin{tabular}{|c|c|c|c|c|c|c|}
\hline \multicolumn{7}{|c|}{ Dependent variable: gasoline consumption } \\
\hline \multirow[t]{2}{*}{ Independent variables } & \multicolumn{2}{|c|}{ Preferred specification } & \multicolumn{2}{|c|}{ With a time trend } & \multicolumn{2}{|c|}{ With time dummies } \\
\hline & Coeff. & Std. err & Coeff. & Std. err. & Coeff. & Std. err \\
\hline Income & $0.195 * * *$ & $(0.042)$ & $0.197 * * *$ & $(0.043)$ & $0.199 * * *$ & $(0.045)$ \\
\hline Real price of gasoline & $-0.137 * *$ & $(0.059)$ & $-0.151 * *$ & $(0.072)$ & $-0.144^{*}$ & $(0.076)$ \\
\hline Population & $0.572 * * *$ & $(0.058)$ & $0.579 * * *$ & $(0.063)$ & $0.557 * * *$ & $(0.068)$ \\
\hline Passenger cars & $0.293 * * *$ & $(0.064)$ & $0.276 * * *$ & $(0.081)$ & $0.293 * * *$ & $(0.086)$ \\
\hline Road network & $0.088 * * *$ & $(0.032)$ & $0.086^{* *}$ & $(0.033)$ & $0.098 * * *$ & $(0.036)$ \\
\hline Constant & $10.851^{* * *}$ & $(0.580)$ & $10.824 * * *$ & $(0.590)$ & $-10.828^{* * *}$ & $(0.622)$ \\
\hline Time trend & - & - & 0.003 & $(0.009)$ & - & - \\
\hline DummyTime05 & - & - & - & - & 0.026 & $(0.101)$ \\
\hline DummyTime06 & - & - & - & - & -0.061 & $(0.090)$ \\
\hline DummyTime07 & - & - & - & - & -0.099 & $(0.091)$ \\
\hline DummyTime08 & - & - & - & - & -0.069 & $(0.095)$ \\
\hline DummyTime09 & - & - & - & - & -0.039 & $(0.099)$ \\
\hline DummyTime10 & - & - & - & - & -0.074 & $(0.099)$ \\
\hline DummyTime11 & - & - & - & - & -0.089 & $(0.103)$ \\
\hline DummyTime12 & - & - & - & - & -0.031 & $(0.106)$ \\
\hline DummyTime13 & - & - & - & - & 0.006 & $(0.115)$ \\
\hline DummyTime14 & - & - & - & - & 0.024 & $(0.111)$ \\
\hline R-squared & 0.98500 & & 0.98500 & & 0.88640 & \\
\hline Adjusted R-squared & 0.98370 & & 0.98340 & & 0.98200 & \\
\hline Standard error of regression & 0.14519 & & 0.14635 & & 0.15259 & \\
\hline Akaike information criterion & -57.64543 & & -55.77522 & & -43.67509 & \\
\hline
\end{tabular}

The table shows the estimated coefficients and their standard errors

The *,**, and *** denote statistical significance at the $10 \%, 5 \%$, and $1 \%$ level

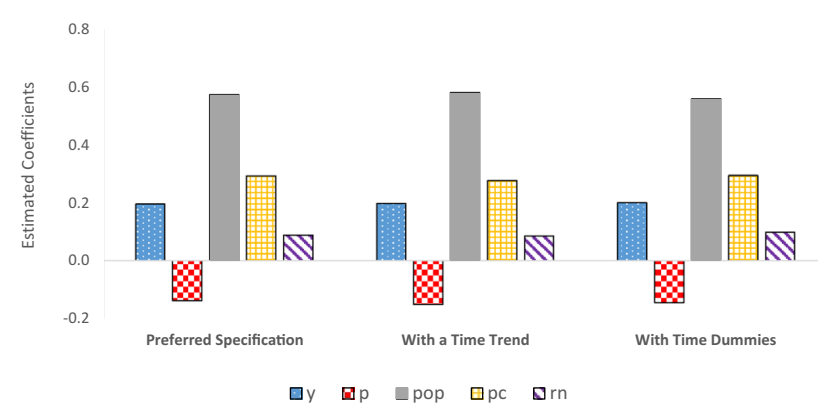

Fig. 4 Estimated coefficients for three specifications of the gasoline demand model

residential electricity, neither the time trend nor the time dummies were included in the preferred specification.

\section{References}

1. World Bank: World Bank Open Data. World Bank, USA (2018)

2. IEA: World energy balances. International Energy Agency, France (2018)
3. IEA: Energy efficiency market report 2016. International Energy Agency, France (2016)

4. Lahn, G.: Targets to promote energy savings in the Gulf Cooperation Council states. Energy Strategy Rev 2(1), 19-30 (2013)

5. SASO: Saudi Energy Efficiency Program. Working session on the implementation of the modified Saudi standard SASO 2663/2012: energy labelling and minimum energy performance requirements for air-conditioners. Saudi Standards, Metrology, and Quality Organization, Saudi Arabia (2013)

6. SASO: SASO Standard 2663. SASO, Saudi Arabia (2018)

7. Davis, L.: Evidence of a decline in electricity Use by US households. Econ Bull 37(2), 1098-1105 (2017)

8. Filippini, M., Hunt, L.C.: Energy demand and energy efficiency in the OECD countries: a stochastic demand frontier approach. Energy J 32(2), 59-80 (2011)

9. Filippini, M., Hunt, L.C.: Measurement of energy efficiency based on economic foundations. Energy Econ 52, S5-S16 (2015)

10. Coelli, T., Prasada Rao, D.S., O’Donnell, C., Battese, G.: An introduction to efficiency and productivity analysis, 2nd edn. Springer, USA (2005)

11. Kumbhakar, S., Wang, H., Horncastle, A.: A practitioner's guide to stochastic Frontier analysis using Stata. Cambridge University Press, Cambridge (2015)

12. Lampe, H., Hilgers, D.: Trajectories of efficiency measurement: a bibliometric analysis of DEA and SFA. Eur J Oper Res. 240, 1-21 (2015)

13. Murillo-Zamorano, L., Vega-Cervera, J.: The use of parametric and non-parametric frontier methods to measure the productive 
efficiency in the industrial sector: a comparative study. Int J Prod Econ 69, 265-275 (2001)

14. Boyd, G.A.: Estimating plant level energy efficiency with a stochastic frontier. Energy J 29(2), 23-43 (2008)

15. Filippini, M., Hunt, L.C.: US residential energy demand and energy efficiency: a stochastic demand frontier approach. Energy Econ 34(5), 1484-1491 (2012)

16. Filippini, M., Hunt, L.C., Zoric, J.: Impact of energy policy instruments on the estimated level of underlying energy efficiency in the EU residential sector. Energy Policy 69, 73-81 (2014)

17. Alberini A, Filippini M (2015) Transient and persistent energy efficiency in the US residential sector: evidence from householdlevel data. CER-ETH Economics Working Paper, ETH Zürich

18. Filippini, M., Hunt, L.C.: Measuring persistent and transient energy efficiency in the US. Energy Effic 9(3), 663-675 (2016)

19. Lundgren, T., Marklund, P.O., Zhang, S.: Industrial energy demand and energy efficiency-evidence from Sweden. Resour Energy Econ 43, 130-152 (2016)

20. Otsuka, A.: Determinants of efficiency in residential electricity demand: stochastic frontier analysis on Japan. Energy Sustain Soc 7(1), 31 (2017)

21. Zhou, P., Ang, B.W., Zhou, D.Q.: Measuring economy-wide energy efficiency performance: a parametric frontier approach. Appl Energy 90(1), 196-200 (2012)

22. Adetutu, M., Glass, A., Weyman-Jones, T.: Economy-wide estimates of rebound effects: evidence from panel data. Energy $\mathbf{J}$ 37(3), 251-269 (2016)

23. Otsuka, A., Goto, M.: Estimation and determinants of energy efficiency in Japanese regional economies. Reg Sci Policy Pract 7(2), 89-101 (2015)

24. Marin, G., Palma, A.: Technology invention and adoption in residential energy consumption: a stochastic frontier approach. Energy Econ 66, 85-98 (2017)

25. Kipouros, P.: Energy efficiency and the rebound effect in developing countries. Dissertation submitted to the Surrey Energy Economics Center (2017)

26. Lin, B., Wang, X.: Exploring energy efficiency in China's iron and steel industry: a stochastic frontier approach. Energy Policy 72, 87-96 (2014)

27. Lin, B., Du, K.: Technology gap and china's regional energy efficiency: a parametric metafrontier approach. Energy Econ 40, 529-536 (2013)

28. Lin, B., Long, H.: A stochastic frontier analysis of energy efficiency of China's chemical industry. J Clean Prod 87, 235-244 (2015)

29. Shen, X., Lin, B.: Total factor energy efficiency of china's industrial sector: a stochastic frontier analysis'. Sustainability 9(4), 646 (2017)

30. Broadstock, D.C., Li, J., Zhang, D.: Efficiency snakes and energy ladders: a (meta-) frontier demand analysis of electricity consumption efficiency in Chinese households. Energy Policy 91, 383-396 (2016)

31. Filippini, M., Zhang, L.: Estimation of the energy efficiency in Chinese provinces. Energy Effic 9(6), 1315-1328 (2016)

32. Settlage, D.M., Dixon, B.L., Thomsen, M.R.: A Comparison Of Various Frontier Estimation Methods Under Differing Data Generation Assumptions. University of Arkansas, Arkansas (2000)

33. Richmond, J.: Estimating the efficiency of production. Int Econ Rev 15(2), 515-521 (1974)

34. Pollitt, M.: The role of efficiency estimates in regulatory price reviews: Ofgem's approach to benchmarking electricity networks. Util Policy 13(4), 279-288 (2005)

35. Giraleas, D., Emrouznejad, A., Thanassoulis, E.: Productivity change using growth accounting and frontier-based approachesevidence from a Monte Carlo analysis. Eur J Oper Res 222, 673 $683(2012)$
36. Arab Union of Electricity: Electricity tariff in the Arab countries. Arab Union of Electricity, Jordan (2008)

37. Arab Union of Electricity: Electricity Tariff in the Arab Countries. Arab Union of Electricity, Jordan (2012)

38. Arab Union of Electricity: Electricity tariff in the Arab countries. Arab Union of Electricity, Jordan (2014)

39. Dynamic EWS. Abu Dhabi Electricity Tariffs. http://www.dynam ic-ews.com/Tariffs/Electricity\%20Tariffs/abudhabi.pdf. Accessed on 28 Jan 2018

40. ECRA: Activities and Achievements of the Authority in 2013. The Electricity \& Co-Generation Regulatory Authority, Saudi Arabia (2013)

41. Meier, A., Sabeeh, S.,Darwish, M.: Complexities of saving energy in Qatar. In: Foundations of Future Energy Policy, ECEEE Summer Study Proceedings, pp. 41-46. (2013)

42. RT. Kuwait Raises electricity and water prices for the first time in 50 years (translated from Arabic). https://ar.rt.com/hjz8. Accessed on 28 Jan 2018

43. IMF: United Arab Emirates: recent economic developments. International Monetary Fund, USA (1999)

44. Al-Iriani, M. and Al-Maamari, E.: A Primer on Dubai's Energy Sector. In: The Economy of Dubai, Oxford University Press (2016)

45. Trade Arabia. Bahrain launches gasoline octane e-service. http:// www.tradearabia.com/news/OGN_208219.html. Accessed on 28 Jan 2018

46. Masress. Saudi Arabia is the cheapest in comparison to world prices, Bahrain is the third in the Gulf in the price of gasoline (translated from Arabic). Available at: http://www.masress.com/ elakhbar/11835. Accessed on 28 Jan 2018

47. Nakono. Average Household Size (68 countries). https://www. nakono.com/tekcarta/databank/households-average-householdsize/. Accessed on 28 Jan 2018

48. NCSI: The final findings of the household expenditure and income survey. National Centre for Statistics and Information, Oman (2012)

49. Climate Change Knowledge Portal. World Bank, USA (2018)

50. OICA. Vehicles in use. http://www.oica.net/category/vehicles-inuse/. Accessed on 28 Jan 2018

51. WRS: World Road statistics millennium data (2000-2014). International Road Federation, USA (2016)

52. SESRIC. The OIC Statistics (OICStat) Database. http://www.sesri c.org/oicstat.php. Accessed on 2828 Jan 2018

53. Secretariat General of the GCC, 2018. GCC Statistics. http://www. gcc-sg.org/ar-sa/CognitiveSources/GulfDatabases/pages/GulfI nformationwithCategorization.aspx. Accessed on 28 Jan 2018

54. Barrington-Leigh, C., Millard-Ball, A.: The world's user-generated road map is more than $80 \%$ complete. PLOS One 12(8), e0180698 (2017)

55. Geofabrik. GCC States-OSM data dump. http://download.geofa brik.de/asia/gcc-states.html. Accessed on 28 Jan 2018

56. Pesaresi, M., Ehrilch, D., Florczyk, A.J., Freire, S., Julea, A., Kemper, T., Soille, P., Syrris, V.: GHS built-up grid, derived from Landsat, multitemporal (1975, 1990, 2000, 2014). European Commission, Joint Research Centre (JRC) (2015). http://data.europ a.eu/89h/jrc-ghsl-ghs_built_ldsmt_globe_r2015b. Accessed on 28 Jan 2018

57. Atalla, T.N., Hunt, L.C.: Modelling residential electricity demand in the GCC countries. Energy Econ 59, 149-158 (2016)

58. Atalla, T.N., Gasim, A.A., Hunt, L.C.: Gasoline demand, pricing policy, and social welfare in Saudi Arabia: a quantitative analysis. Energy Policy 114, 123-133 (2018) 